\title{
Men and postmenopausal women with iron deficiency had increased risk of gastrointestinal malignancy
}

Ioannou GN, Rockey DC, Bryson CL, Weiss NS. Iron deficiency and gastrointestinal malignancy: a population-based cohort study. Am J Med 2002;113:276-80.

\section{QUESTION: Does iron deficiency, with or without anaemia, increase the risk of gastrointestinal malignancy?}

\author{
Design \\ Cohort study with 2 years of follow up. \\ Setting \\ USA.
}

\section{Participants}

9024 civilian, non-institutionalised persons 25-74 years of age (60\% women, $83 \%$ white) who participated in the National Health and Nutrition Examination Survey (NHANES I) and the NHANES I Epidemiologic Followup Study (NHEFS). Exclusion criteria were a history of cancer reported during NHANES I and missing iron saturation and haemoglobin measurements at baseline.

\section{Assessment of risk factors}

Baseline data were collected on iron deficiency (iron saturation $<15 \%$ ) and anaemia (haemoglobin concentration $<5$ th percentile for each age and sex group). Separate analyses were done for premenopausal women, men and postmenopausal women, age $\geq 50$ years, and age $\geq 65$ years. Within each group, participants were grouped into 4 diagnostic categories based on their anaemia and iron deficiency status.

\section{Main outcome measures}

Diagnosis of gastrointestinal malignancy (ie, any malignancy of the oesophagus, stomach, small intestine, colon, or rectum) within 2 years of measurement of iron saturation and haemoglobin concentrations. Outcome assessors were blinded to iron saturation concentrations.

no external funding.

For correspondence: Dr G N Ioannou,

Veterans Affairs

Medical Center, Seattle,

WA, USA.

georgei@

medicine.washington.edu

Abstract and

commentary also

appear in ACP Journal

Club.

Risk of gastrointestinal malignancy in persons with iron deficiency (ID) and ID anaemia (IDA)

\begin{tabular}{lll}
$\begin{array}{l}\text { Group and comparison } \\
\begin{array}{l}\text { Men and postmenopausal } \\
\text { women }\end{array}\end{array}$ & Relative risk $(95 \% \mathrm{Cl})^{*}$ \\
\hline with ID $v$ control & $1 \% v 0.2 \%$ & $5.0(1.0$ to 21$)$ \\
\hline with IDA $v$ control & $6 \% v 0.2 \%$ & 31 (9 to 107$)$ \\
\hline Age $\geq \mathbf{5 0}$ years & $1.3 \% v 0.3 \%$ & $5.0(1.1$ to 21$)$ \\
\hline with ID $v$ control & $6 \% v 0.3 \%$ & $22(6$ to 78$)$ \\
\hline with IDA $v$ control & $2.3 \% v 0.4 \%$ & $6.0(1.3$ to 26$)$ \\
\hline Age $\geq \mathbf{6 5}$ years & $9 \% v 0.4 \%$ & $24(7$ to 81$)$ \\
\hline with ID $v$ control &
\end{tabular}

\section{Main results}

716 participants (8\%) were iron deficient; of these, 143 $(1.6 \%)$ were also anaemic. 18 participants $(0.2 \%)$ had a diagnosis of gastrointestinal malignancy during the 2 year follow up.

None of the 2708 premenopausal women had gastrointestinal malignancy at 2 years. Men and postmenopausal women $(\mathrm{n}=6227)$ with iron deficiency alone $(\mathrm{n}=223)$ and iron deficiency anaemia $(\mathrm{n}=51)$ had

${ }^{*}$ Control = patients without ID or IDA; CI defined in glossary. increased risk of gastrointestinal malignancy (table). Similar results were found for persons $\geq 50$ years of age $(n=4447)$ and those $\geq 65$ years of age $(n=2733)$ (table).

\section{Conclusion}

Men and postmenopausal women with iron deficiency, with or without anaemia, had increased risk of gastrointestinal malignancy at 2 years.

\section{COMMENTARY}

In western countries, it is standard practice to recommend thorough gastrointestinal investigation for unexplained iron deficiency anaemia in all patients, except some premenopausal women. The yield in terms of detection of serious conditions has been as high as $30 \%$ in some series. However, these studies were not population based and primarily included selected cases referred to hospital, often with occult blood positive stools. ${ }^{1}$ Recently, some clinicians have advocated investigation of iron deficiency in the absence of anaemia, a condition that is far more prevalent than iron deficiency anaemia $(6.4 \% v 1.6 \%) .^{23}$

Ioannou et al took advantage of data collected in the NHANES on haemoglobin and iron status to examine the risk of gastrointestinal malignancy in patients with iron deficiency alone. As shown in the abstract table, risk of gastrointestinal cancer was $>5 \%$ only in patients with iron deficiency anaemia. As expected, 13 of the 18 cases of cancer found were colorectal. All occurred in patients $\geqslant 50$ years of age, and none occurred in premenopausal women. Although the relative risk for gastrointestinal cancer was increased in patients with iron deficiency without anaemia, absolute risk was modest at $1-2.3 \%$ depending on the subgroup.

The study by Ioannou et al provides firm evidence to support thorough gastrointestinal investigation in patients with iron deficiency anaemia. It also shows that investigation of patients incidentally found to be iron deficient (ie, with no other indications of gastrointestinal disease) will have a low yield in terms of detection of gastrointestinal malignancy. Whether this low yield is sufficient to justify investigation will depend on the healthcare system and who is paying. As colorectal cancer screening is now recommended in some countries, such as the US, perhaps the bottom line is that any person $>50$ years of age found to be iron deficient should be encouraged to have a colonoscopy as part of routine colorectal cancer screening.

Richard F Logan, MD University of Nottingham, Nottingham, UK

1 Zuckerman GR, Prakash C, Askin MP, et al. AGA technical review on the evaluation and management of occult and review on the evaluation and management of occult and
obscure gastrointestinal bleeding. Gastroenterology obscure gastrointestinal bleeding. Gastroenterology
2000;118:201-21.

2 Lee JG, Sahagun G, Oehlke MA, et al. Serious gastrointestinal pathology found in patients with serum ferritin values $<$ or $=50 \mathrm{ng} / \mathrm{ml}$. Am J Gastroenterol 1998;93:772-6.

3 Wilcox CM, Alexander LN, Clark WS. Prospective evaluation of the gastrointestinal tract in patients with iron deficiency and no systemic or gastrointestinal symptoms or signs. Am J Med 1997;103:405-9. 